\title{
A Construção da Rede Nacional de Pesquisa em Documentação Patrimonial Cultural
}

\section{The Construction of a national Research network in CUltural heritage DOCUMENTATION}

\author{
(iD) $\theta$ \\ Alcilia Afonso \\ Universidade Federal de Campina Grande (UFCG) , Campina Grande, Paraíba, Brasil \\ kakiafonso@hotmail.com
}

Resumo

O artigo possui como tema, a discussão sobre a documentação do patrimônio cultural brasileiro, que vem sendo consolidada através do trabalho do comitê científico nacional do Icomos Brasil/IcomosDoc, que entre suas distintas ações, vem atuando para a construção de uma rede nacional de pesquisas que possui como objetivo, documentar o acervo patrimonial do país, em suas mais distintas regiões geográficas, realizando conexões entre as mesmas. Os dossiês temáticos são compostos de artigos de especialistas que atuam na área, apresentando resultados dos trabalhos desenvolvidos em projetos de pesquisas, ou em ações técnicas realizadas não apenas pelos membros do IcomosDoc, mas também, de outros profissionais e ativistas patrimoniais nacionais. Os dossiês estão sendo publicados em periódicos vinculados aos programas de pós-graduação de universidades brasileiras, que vêm apoiando a iniciativa e abrindo um canal para publicação do material organizado pela coordenação do comitê em parceria com os editores de cada revista, conforme será visto no artigo.

Palavras-chave: Documentação. Pesquisa patrimonial. Patrimônio cultural. Patrimônio histórico. Preservação patrimonial.

\begin{abstract}
The article has as its theme the discussion on the documentation of Brazilian cultural heritage, which has been consolidated through the work of the national scientific committee of Icomos Brazil/IcomosDoc, which among its different actions, has been working to build a national network of research that aims to document the country's heritage, in its most distinct geographic regions, making connections between them. The thematic dossiers are composed of articles by specialists who work in the area, presenting the results of the work developed in research projects, or in technical actions carried out not only by IcomosDoc members, but also by other national heritage professionals and activists. The dossiers are being published in journals linked to postgraduate programs at Brazilian universities, which have been supporting the initiative and opening a channel for the publication of material organized by the coordination of committee in partnership with the editors of each journal, as will be seen in the article.
\end{abstract}

Keywords:Documentation. Heritage research. Cultural heritage. Historical heritage. Heritage preservation. 


\section{Introdução}

O artigo possui como tema a documentação do patrimônio cultural brasileiro, que vem sendo consolidada através do trabalho do comitê científico nacional do Icomos Brasil/ Icomos Doc, que entre suas distintas ações, vem atuando para a consolidação de uma rede nacional de pesquisas que possui como objetivo, documentar o acervo patrimonial do país em suas mais distintas regiões geográficas.

As ações de conscientização e sensibilização vêm sendo realizadas através de diversas maneiras, entre elas, a elaboração de dossiês temáticos, que são compostos de artigos de especialistas que atuam na área, apresentando resultados dos trabalhos desenvolvidos em projetos de pesquisas, ou em ações técnicas desenvolvidas, não apenas pelos membros do comitê, mas também, de outros profissionais e ativistas patrimoniais.

Justifica-se apresentar o tema nesse artigo, como maneira de socializar a importância dos produtos e ações do Icomos Doc, trazendo à tona, as discussões mais presentes nos trabalhos que compuseram estes dossiês temáticos, observandose as pautas atualizadas do discurso teórico e prático- bem como, outros dados de interesse resultantes dessa ação.

Acredita-se que documentar é um dos primeiros passos para o processo de preservação de nosso patrimônio cultural, seja ele, material ou imaterial, e partindo-se dessa premissa, divulga-se o resultado dessa etapa nas ações do IcomosDoc.

Como metodologia da pesquisa que levantou dados sobre tais dossiês, foi empregada a pesquisa exploratória, desenvolvida com o objetivo de proporcionar uma visão geral, de tipo aproximativo, acerca do material produzido. Gil (2008, p.27 ) explica que "este tipo de pesquisa é realizado especialmente quando o tema escolhido é pouco explorado e torna-se difícil sobre ele formular hipóteses precisas e operacionalizáveis".

Gil continua explicando que: 


\begin{abstract}
Muitas vezes as pesquisas exploratórias constituem a primeira etapa de uma investigação mais ampla. Quando o tema escolhido é bastante genérico, tornam-se necessários seu esclarecimento e delimitação, o que exige revisão da literatura, discussão com especialistas e outros procedimentos. (GIL. 2008, p.27)
\end{abstract}

Dessa maneira, a coleta do material foi realizado no acervo digital do IcomosDoc, bem como nos sites dos periódicos que publicaram os dossiês temáticos, como por exemplo, os das revistas Jatobá/ UFG (onze artigos); Mnemosine/ UFCG (dez artigos); Labor \& Engenho/ UNICAMP (seis artigos num primeiro dossiê de 2020, e doze artigos no segundo dossiê de 2021); Ciência e Tecnologia/ UFRR (treze artigos); Museion / Uni La Salle de Canoas/ RS (catorze artigos no primeiro dossiê e dezesseis, no segundo dossiê para a Revista).

Após a coleta da listagem de artigos publicados em cada um dos dossiês, foi realizado o levantamento de dados autorais e temáticos de cada um dos trabalhos, para fornecer elementos para as análises.

As análises iniciais da pesquisa visaram observar os temas mais presentes na discussão sobre documentação patrimonial cultural e que têm sido objetos de estudos dos autores envolvidos, que possuem em sua maioria, perfil profissional de arquitetos e urbanistas, e atuam como professores e pesquisadores acadêmicos; de historiadores; paisagistas; estudantes de graduação e pós-graduação, e também em sua maioria, vinculados a cursos de arquitetura e urbanismo.

Outra observação sobre estes autores é que a maior parte está vinculada a programas de pós-graduação em universidades brasileiras, que são na maioria, públicas e federais. Observa-se que tal cenário é decorrente da exigência de doutores nas autorias dos artigos publicados nos periódicos científicos, e que estes- muitas vezes convidam os seus orientandos dos programas de pós-graduação e da graduação (via projetos de iniciação científica) para apresentarem os resultados das pesquisas desenvolvidas em conjunto.

Como os dossiês temáticos fazem parte do plano de ação da gestão do IcomosDoc, a maior parte dos artigos pertence aos membros do comitê que sempre 
são convidados e provocados a desenvolver esse trabalho de socialização das informações.

Importante registrar aqui, que o aporte teórico da discussão sobre o papel da documentação na preservação patrimonial se baseia nas Cartas Patrimoniais (Cury, 2000), bem como, nas normas do Icomos e nas discussões mais recentes sobre o papel das tecnologias digitais e analógicas na contemporaneidade, presentes em publicações contidas nos anais do CIPA Heritage Documentation e nas webinars realizadas pelo IcomosDoc (Icomos, 2020).

Observa-se que:

Os arquivos documentais dos monumentos, conjuntos arquitetônicos e sítios históricos e artísticos podem incluir testemunhos, tanto materiais como imateriais, e representam uma parte da documentação que pode contribuir para a compreensão do patrimônio cultural e aos valores dos quais este é portador. (ICOMOS, 1996, p.1).

A documentação pode ser entendida como a fase inicial do trabalho de preservação cultural, e observa-se a importância desse princípio que vem sendo apoiado e difundido em nível internacional pelo CIPA/ Comité International de la Photogrammétrie Architecturale, fundado em 1968, e que ao longo dos anos vem com seus membros aplicando tecnologia de medição, visualização e ciências da computação para o benefício de registrar, conservar e documentar o patrimônio cultural em todas as suas formas possíveis, fato que significou um grande avanço para o resgate da paisagem, natural e construída com interesse patrimonial.

O CIPA é uma organização internacional que possui duas responsabilidades: a) manter-se atualizado com a tecnologia; b) e garantir sua utilidade para a conservação, educação e disseminação do patrimônio cultural. Esta dupla função está presente em suas duas organizações principais: ICOMOS (Conselho Internacional de Monumentos e Locais) e o ISPRS (Sociedade Internacional de Fotogrametria e Sensoriamento Remoto). 
As discussões que estão presentes nas ações do CIPA influenciam o trabalho da documentação em todos os continentes, considerando que em seu estatuto (CIPA, STATUTES, 2019, p.3), um de seus objetivos é estabelecer pontes entre o trabalho de profissionais, como arquitetos, historiadores, arqueólogos, especialistas das áreas de ferramentas digitais que atuam como computação gráfica, laser scanner, por exemplo- e que juntos contribuem para o trabalho de preservação cultural através da organização e sistematização de documentação analógica e digital.

Almejam ainda organizar a disseminação e trocas de ideias, experiências, com resultados da pesquisa e do conhecimento, estabelecendo contatos com e entre relevantes instituições e companhias que apoiem o trabalho. No Brasil, os objetivos do CIPA vêm sendo desenvolvidos por membros que compõem IcomosDoc, conforme será visto a seguir.

\section{As Ações do Comitê Científico Nacional de Documentação do Icomos Brasil}

O Comitê Brasileiro do Conselho Internacional de Monumentos e Sítios/ Icomos Brasil após a reforma dos seus estatutos em 1995, é uma organização não governamental, sem fins lucrativos e agindo em nome do interesse público. Em 2021, o Icomos Brasil tem cerca de 450 membros individuais, que formam uma comunidade multidisciplinar de peritos reconhecidos, entre os quais se incluem arquitetos, engenheiros, artistas, arqueólogos, historiadores juristas, que trabalham em diversos campos do patrimônio cultural, na sua conservação, gestão e promoção.

De acordo com seu Estatuto (ICOMOS BRASIL, 2020) e em conformidade com os objetivos e atribuições do Icomos - "a organização internacional a que pertence, o Icomos Brasil realiza uma ampla gama de atividades, que inclui a promoção de seminários e cursos, a publicação de livros e periódicos, a avaliação de monumentos e sítios patrimoniais, entre outros." Possui catorze comitês científicos direcionados 
aos temas preservacionistas, e entre eles, está inserido o comitê científico nacional de documentação do Icomos Brasil, o IcomosDoc.

O IcomosDoc possui como missão, o estudo e a difusão das técnicas e tecnologias aplicadas à documentação para a conservação do patrimônio cultural. Em especial as que são úteis nas etapas de aquisição de dados, de processamento científico e a disseminação das informações.

Analisando o plano de ação do IcomosDoc (Icomos Brasil, 2020) observa-se as prioridades para cadastrar novos pesquisadores brasileiros e estrangeiros; mapear os objetos de pesquisa, técnicas, tecnologias que estão sendo utilizadas pelos membros; criar um banco de dados como repositório de pesquisas, livros, artigos, relatórios, dissertações e teses; buscar aproximação com o CIPA-ICOMOS internacional.; alimentar o site do Icomos Brasil na área de documentação; incentivar pesquisadores para participar do comitê.

Analisando o banco de dados do IcomosDoc, observou-se que em setembro de 2021, o comitê de documentação possui quarenta membros inscritos (Figura 1), sendo trinta e quatro membros graduados em arquitetura e urbanismo, dois historiadores, um biólogo, um jornalista, um filósofo e um designer.
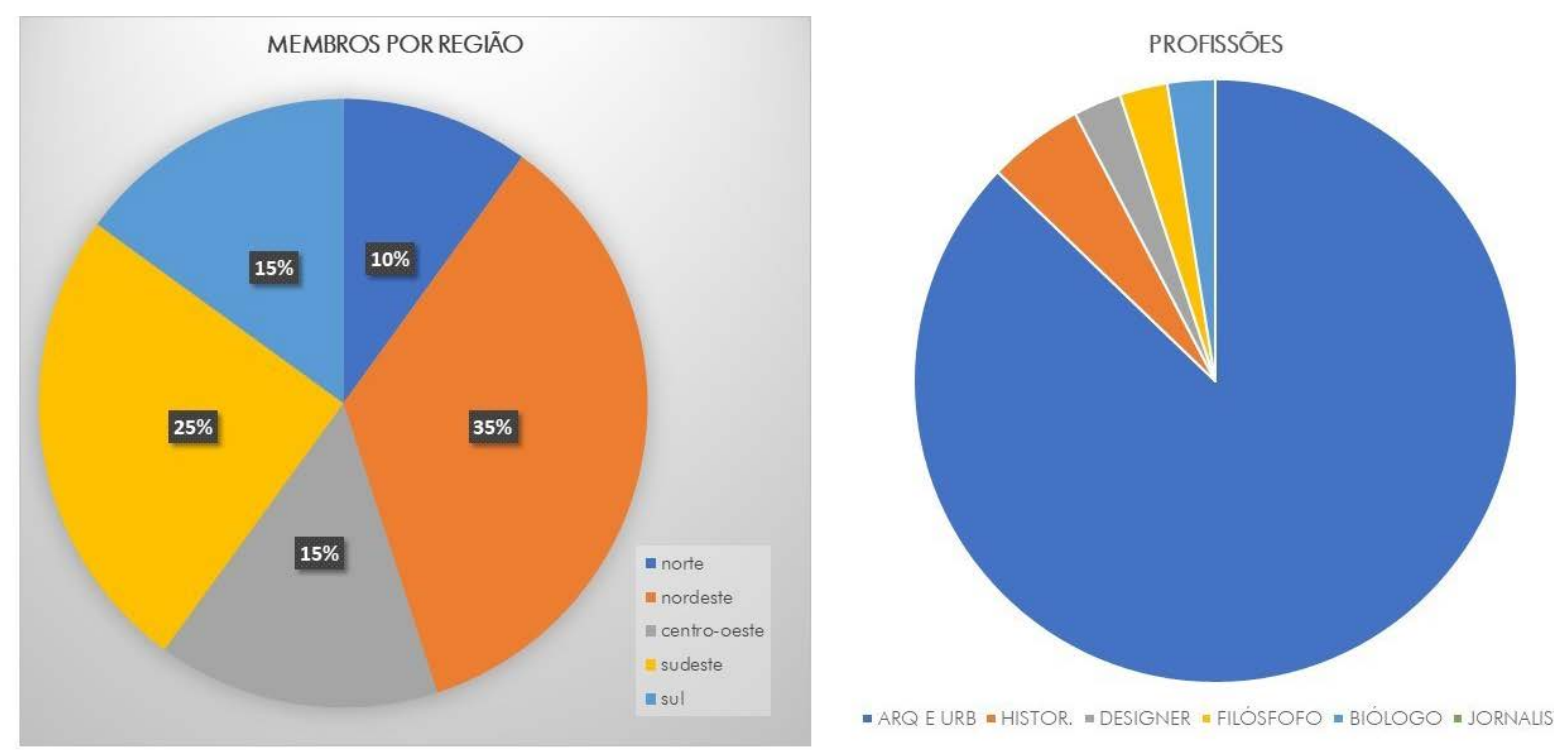

Figura 1- Gráficos da constituição de membros do IcomosDoc por região e por profissões Fonte: Elaboração da autora. 2021. 
Tal quadro demonstra que o tema da documentação arquitetônica e urbanística tem a cada dia que passa, se fortalecido no trabalho de preservação patrimonial, incrementado por organismos como o Docomomo Brasil, que há anos trabalha com o resgate documental da modernidade brasileira.

Quanto à representatividade regional presente no IcomosDoc observou-se que a maior parte dos membros são nordestinos (catorze); seguidos de dez membros da região sudeste, seis das regiões sul e centro-oeste, respectivamente; e quatro do norte brasileiro. Analisando-se tal amostragem observa-se que, talvez, pela atual coordenadora do IcomosDoc ser nordestina, a mesma convidou colegas de instituições de ensino e pesquisadores da região que já atuam a anos na área, aumentando assim, a participação local no comitê.

Da região norte, os estados de Rondônia, Amapá. Tocantins e Acre não possuem representantes, mesmo havido sido contactados e convidados. No nordeste, apenas o Rio Grande do Norte, não demonstrou interesse em participar. No centro-oeste, os estados do Mato Grosso, e Mato Grosso do Sul também, não estão presentes, também havendo sido contactados e convidados. O Espírito Santo não possui nenhuma representação no comitê, e na região sul, apenas Santa Catarina não participa.

Qual seria a causa dessas ausências na discussão sobre documentação patrimonial nesses estados? Uma hipótese a ser aprofundada pode ser referente à pouca existência de cursos de graduação e pós-graduação na área que dialoga mais diretamente com o patrimônio cultural, tais como arquitetura e urbanismo, e história, principalmente.

Observou-se ainda que os membros do IcomosDoc são na maioria vinculados às Universidades públicas federais e estaduais, sendo um percentual mínimo vinculado ao IPHAN/ Instituto do Patrimônio Histórico e Artístico Nacional, ou às prefeituras.

Entre as ações do IcomosDoc, as webinars produzidas em 2020 (Icomos, 2020) foram de grande importância para o fortalecimento das discussões das áreas de maior 
crescimento na contemporaneidade na área documental e contribuem como aporte teórico e prático nesse artigo.

\section{Dossiês Temáticos}

Os dossiês temáticos que tratam sobre a documentação do patrimônio cultural estão sendo publicados em periódicos vinculados aos programas de pós-graduação de universidades públicas e privadas brasileiras, que vêm apoiando a iniciativa e abrindo um canal para divulgação do material organizado pela coordenadora do Icomosdoc em parceria com os editores de cada revista.

Estes dossiês foram organizados por mim, como coordenadora do IcomosDoc - em diálogo constante com os editores de cada periódico, seguindo todas as normas estipuladas por eles, prazos, entre outros aspectos. A proposta foi atingir as mais distintas regiões brasileiras, a fim de interiorizar discussões e se aproximar mais de lugares nos quais a informação sobre documentação e a atuação do IcomosDoc ainda não estava devidamente consolidada.

Com o apoio de alguns membros do comitê que facilitaram as tratativas entre o meu trabalho e os editores chefes dos periódicos, foi possível se chegar à montagem dessas publicações que serão vistas sucintamente a seguir. Entre o primeiro semestre de 2020 até o presente momento foram publicados sete dossiês.

\section{Dossiê 1: Revista Jatobá/ UFG. Goiás}

O primeiro dossiê organizado pelo IcomosDoc- intitulado "Dossiê de documentação"- foi publicado na Revista Jatobá, que faz parte do Programa de Pósgraduação Projeto e Cidade (PPGPC) e à Faculdade de Artes Visuais no campus Samambaia, da Universidade Federal de Goiás (figura 2), e teve a minha coordenação em parceria com um dos membros do comitê e editora da Revista, a professora Luana Kallas (Afonso e Kallas, 2020). 

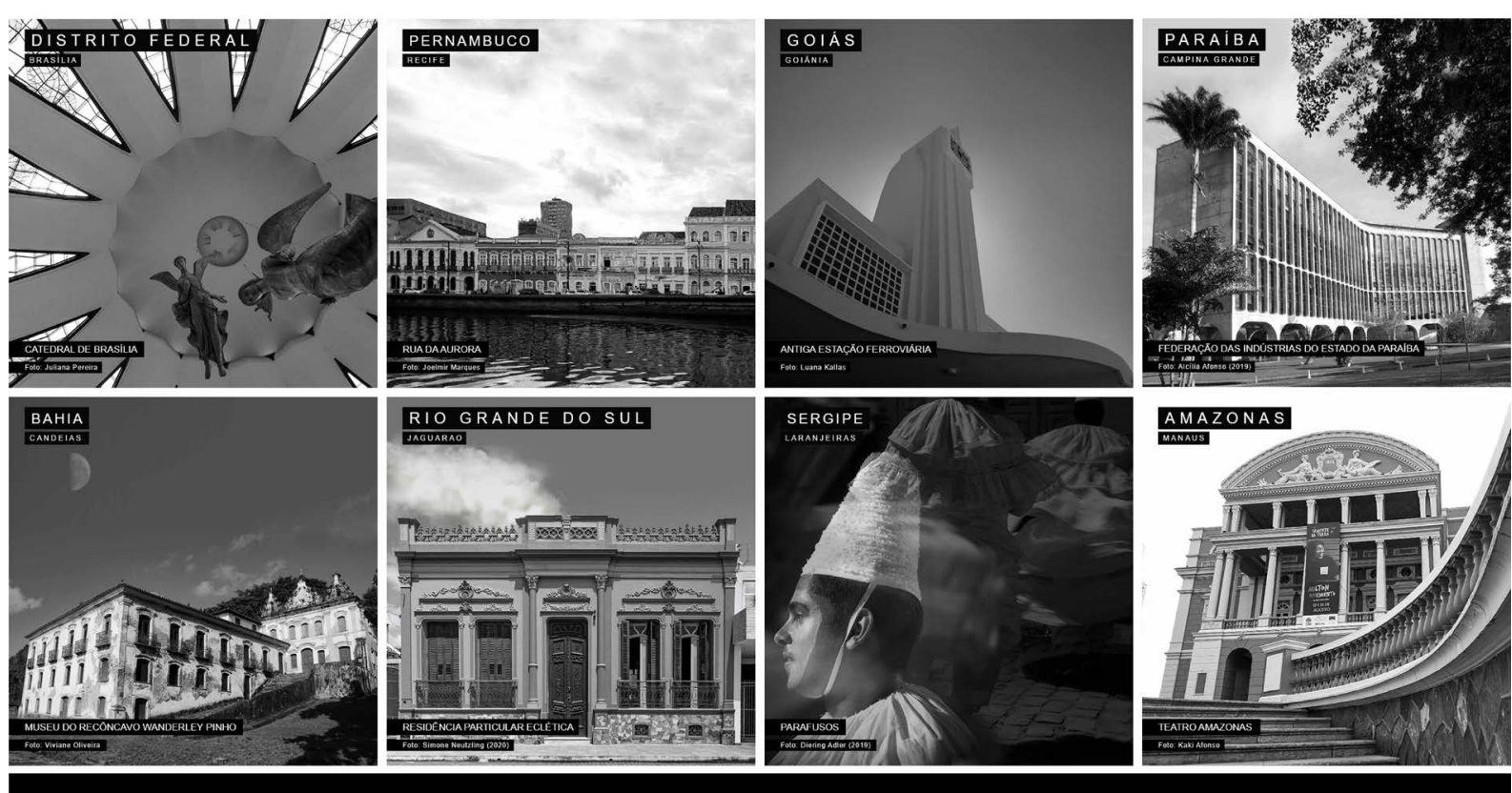

PPGPC FAV UFG

Dossiê de documentação

Figura 2- Capa do dossiê de documentação. Revista Jatobá. Fonte: Acervo do Icomosdoc.2020.

O dossiê gerou uma documentação importante textual e gráfica, de cunho analítico e crítico, através da publicação de onze textos enfocando temas voltados para o resgate documental arquitetônico, paisagístico, urbanístico, de distintos recortes temporais e espaciais brasileiros, dialogando com ferramentas analógicas e digitais que serviram de suporte para ações preservacionistas.

Dos artigos apresentados, seis eram do nordeste, dois do centro-oeste, dois do sudeste e apenas um da região sul. Dos estados nordestinos presentes destacam-se a Paraíba, com dois artigos sobre a documentação em pesquisas sobre a modernidade em Campina Grande; dois elaborados por pesquisadores da UFSE/ Universidade Federal de Sergipe, um elaborado por pesquisadores recifenses e um, pelo Maranhão. O tema da modernidade arquitetônica dominou a discussão documental, motivada pela participação de membros do Docomomo Brasil também no IcomosDoc, fortalecendo assim a importância do resgate documental realizado pelas duas instituições em prol do patrimônio moderno. 
Da região sudeste foram publicados dois trabalhos enfocando a paisagem carioca e sua documentação, trazendo à tona, uma linha recente e muito pertinente que é valorização da paisagem e seu acervo. O único artigo da região sul esteve voltado para discussões sobre a história da arquitetura enfocando o Art Déco; e da região centro-oeste vieram discussões sobre duas linhas: um direcionado para os sketches como ferramentas de apoio à documentação; e o segundo para o debate sobre arquitetura e história.

Observou-se que o norte não enviou nenhum trabalho, e a maior participação foi nordestina, certamente estimulada pelas coordenadoras do dossiê que possuem suas origens nessa região e interagiram bem com demais pesquisadores que se uniram à proposta.

\section{Dossiê 2: Mnemosine /UFCG. Paraíba}

O segundo dossiê foi publicado em 15 de dezembro de 2020, na Revista Mnemosine, vinculada ao Programa de pós-graduação em História da UFCG/ Universidade Federal de Campina Grande na Paraíba e organizado também por mim (Afonso, 2020). Entre os dez artigos publicados, seis foram sobre a documentação no nordeste brasileiro, três da região sudeste e apenas um, do sul.

Mais uma vez sobressaiu-se entre os artigos, a discussão voltada para a documentação da modernidade arquitetônica que esteve presente em quatro artigos voltados para objetos arquitetônicos protomoderno e modernos, presentes nas cidades de Recife, Campina Grande, São Luís, São Paulo: “Esses quatro artigos trataram de casos isolados de profissionais com trajetórias marcantes, ou de conjuntos arquitetônicos" (Afonso, 2020, p.7).

A discussão sobre a documentação de paisagem e patrimônio foram enfocadas em três artigos que trouxeram casos nordestinos de cidades interioranas como Cabaceiras, e Campina Grande, na Paraíba; e Gravatá do Ibiapina, em Pernambuco, 
ricas em seus conjuntos históricos e em seus acervos patrimoniais; Ainda nessa linha de discussão, foi apresentado um trabalho que resgatou a paisagem carioca.

Outros temas, como design, arquitetura vernacular e medievalismo estiveram presentes na composição do dossiê que obteve um excelente resultado editorial tanto no que é referente ao conteúdo, quanto à diagramação do mesmo (figura 3).

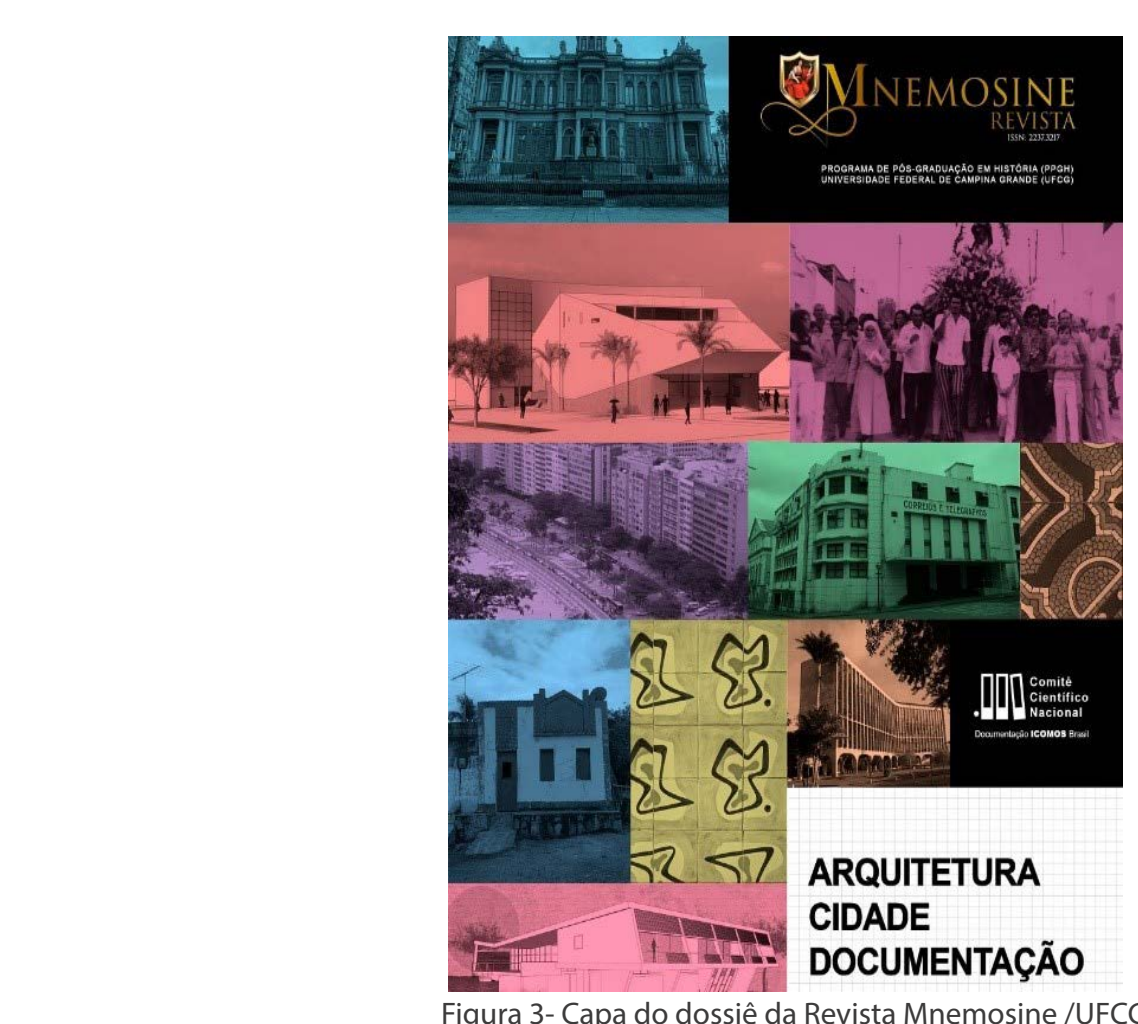

Fonte das imagens:: http://www.mnemosinerevista.com/index.php/revista/issue/view/29/37. Acesso em 26/08/2021.

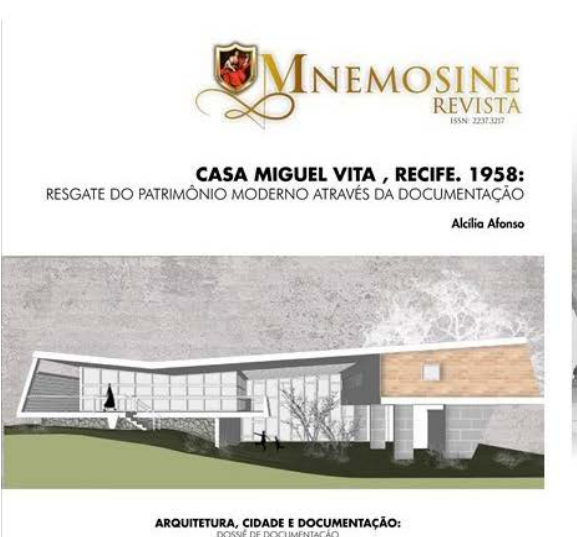

HISTÓRIA ARQUITETURA E DOCUMENTAÇÃO tumono DikOODNII
AlCIIIA AFONSO

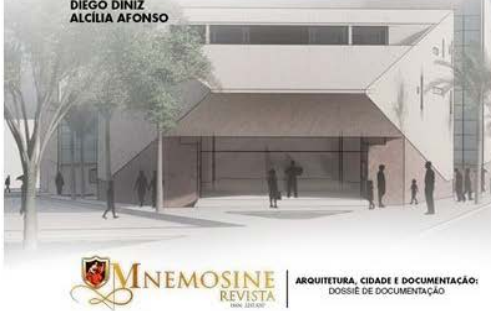

REGISTRO E DOCUMENTAÇÃO DOS
LADRILHOS HIDRAULICOS DO PAÇO MUNICIPAL-RS

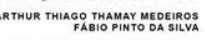

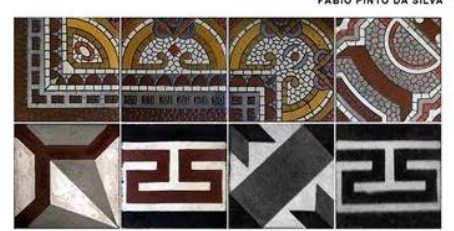

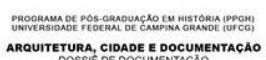

Figura 4 - Alguns posts de publicação de artigos do dossiê da Revista Mnemosine/UFCG. Fonte: Fotomontagem da autora.2021. 
Após a publicação dos artigos em rede, o lcomosDoc realizou um trabalho de divulgação de cada artigo (figura 4) em suas redes sociais como Instagram e Facebook, socializando os resumos dos mesmos e convidando aos interessados a acessarem o conteúdo do periódico para aprofundamentos nas discussões contidas no dossiê.

\section{Dossiê 3: Labor e engenho/ UNICAMP. São Paulo}

O terceiro dossiê foi publicado no final de dezembro de 2020, na Revista Labor e Engenho/ UNICAMP de São Paulo. Organizei em parceria com o editor Dr. André Argollo, sendo o dossiê montado com seis artigos, trazendo dois artigos sobre a documentação patrimonial no México e na França.

O artigo realizado por pesquisadores patrimoniais mexicanos enfocou as questões documentais do planejamento urbano inicial realizado no estado de Veracruz; enquanto o artigo sobre a França, tratou sobre o uso das tecnologias digitais no processo de documentação do patrimônio, tomando como estudo de caso, o vilarejo de Thillois.

O tema do patrimônio industrial por primeira vez veio à tona em um dos dossiês, e tratou sobre a documentação projetual do Centro de Tecnologia do couro e calçado Albano Franco, em Campina Grande/ PB. Outra inovação temática, foi a presença do norte brasileiro nas discussões, com a publicação de um trabalho sobre a arquitetura moderna em Belém, tratando sobre documentos de projeto e testemunho oral como fontes de pesquisa.

E mais uma vez o tema dos Sketches esteve presente como uma forma de documentação, valorização e resgate do patrimônio edificado e urbanístico, tendo como estudo de caso, o plano piloto de Brasília/ DF. A relação entre paisagem e patrimônio se fez presente em artigo sobre o mercado imobiliário e a dinâmica espacial no centro histórico de Campina Grande/PB, enriquecendo a discussão nessa área. 


\section{Dossiê 4: Revista Ciência e Tecnologia / UFRR. Roraima}

O quarto dossiê foi organizado por mim e Dra. Graciete Costa, professora da UFRR/ Universidade Federal de Roraima e membro do IcomosDoc, que viabilizou a publicação em um dossiê intitulado "Documentação do Patrimônio Cultural".

Nossa coordenação do IcomosDoc havia observado uma pouca participação da região norte nas discussões e ações do comitê, e para provocar uma maior integração com a região montou esse dossiê como um mecanismo para dinamizar em Roraima, ações no sentido de interagir com demais universidades e pesquisadores brasileiros.

A estratégia funcionou e conseguiu-se ter três artigos da região norte, sendo dois deles da cidade de Belém do Pará, que iniciou um processo ativo de participação nos dossiês a partir de então. Mas, mesmo assim, observa-se que os demais estados do norte brasileiro, mesmo que procurados e provocados, não possuem a prática de publicação cientifica ou mesmo, anseio em se inserir nos debates patrimoniais.

O dossiê (figura 5) foi composto por treze artigos de autoria dos membros do IcomosDoc com seus parceiros de estudos ou individualmente- que desenvolvem nas cidades nas quais atuam, de estados das mais distintas regiões brasileiras, um importante papel nesse processo preservacionista ao atuarem documentando, e consequentemente, preservando os bens materiais ou imateriais brasileiros.

Da região norte foram apresentados três artigos tratando dos acervos documentais do Pará (2) e de Roraima; do Nordeste, foram seis artigos enfocando casos no Maranhão, Ceará (2), Pernambuco (2), Paraíba; do Centro-Oeste, um artigo direcionado à Brasília; no Sudeste, dois casos, sendo um paulista e outro carioca; e finalmente, da Região Sul, um artigo sobre o trabalho documental em Pelotas /Rio Grande do Sul.

Dos temas apresentados observou-se que a questão dos inventários, que é base de um processo de resgate do acervo patrimonial - está presente no artigo sulista; enquanto que, cinco artigos trataram de um tema bastante contemporâneo nas discussões sobre a documentação do patrimônio cultural que é referente ao uso das 
ferramentas digitais e novas tecnologias, e consiste em difundir as diversas opções com suas possibilidades e benefícios, divulgando a aplicação para os demais objetos que se encontram em distintos estados de conservação, colaborando no entendimento da obra ou conjunto, como forma de resgatar e salvaguardar suas autenticidades.

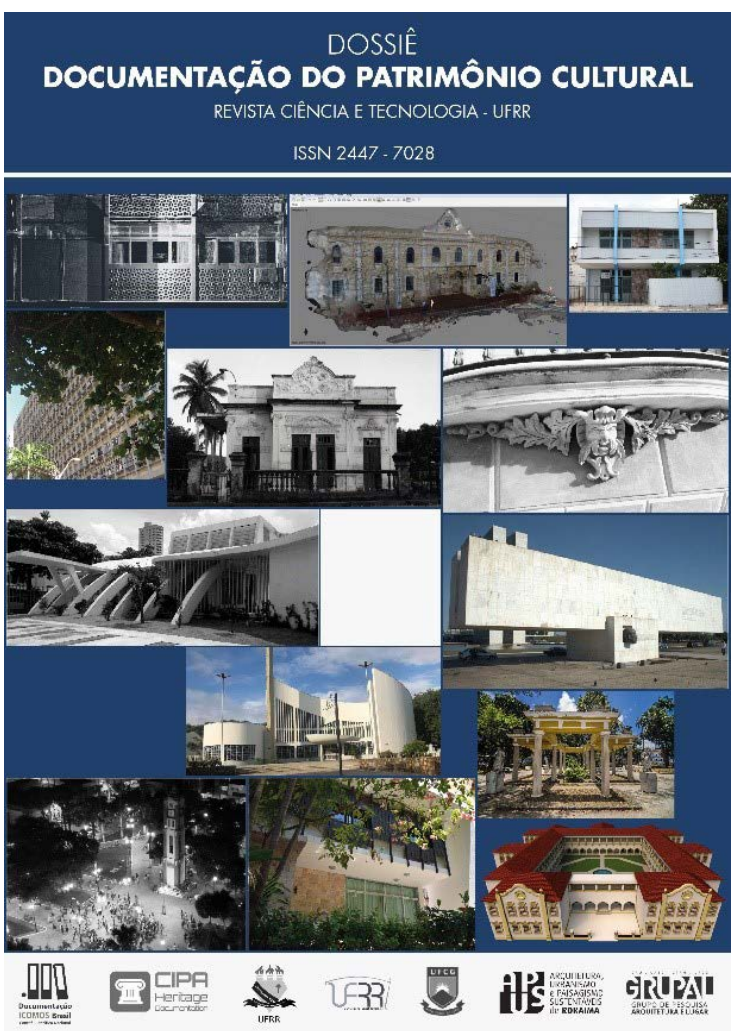

Figura 5 - Capa do dossiê na Revista Ciência e Tecnologia-UFRR.

Fonte: https://revista.ufrr.br/rct/issue/view/318/showToc. Acesso em 20/08/2021

Essa discussão esteve presente nos artigos do Ceará, Paraíba, São Paulo, Rio de Janeiro e Brasília. Questões gerais como os acervos de arquitetura eclética, moderna, também foram marcantes no dossiê com excelentes trabalhos sobre Roraima, Belém do Pará, São Luís, Juazeiro do Norte, Recife, resgatando documentos não apenas arquitetônicos, mas também urbanísticos e paisagísticos, ampliando assim, os debates das reflexões.

O dossiê registrou nesse conjunto de artigos, um panorama do cenário da documentação no Brasil, expondo um pouco dos importantes projetos de pesquisas acadêmicas desenvolvidos sobre o assunto, bem como ações fundamentais, como o da Fundação Joaquim Nabuco de Recife. 


\section{Dossiê 5: Revista Museion/ Uni La Salle. Rio Grande do Sul}

O dossiê intitulado "Documentação do patrimônio cultural_ Dossiê 1" (Figura 6) foi montado em parceria com a Revista Museion do Museu e Arquivo Histórico La Salle da cidade de Canoas no Rio Grande do Sul. Como coordenadora do IcomosDoc, e com a finalidade de realizar uma articulação do comitê com a região sul do Brasil, procurei realizar essa ponte como uma forma de estreitar essa relação.

Havia sido observado nos dossiês passados, que os membros do IcomosDoc que são sulistas, como também, os membros da região norte brasileira, não haviam demonstrado interesse em participar dos dossiês. Pode-se afirmar tal colocação quando se observa o número de participantes da região no comitê (apenas quatro), e o pouco interesse em participar das publicações temáticas.

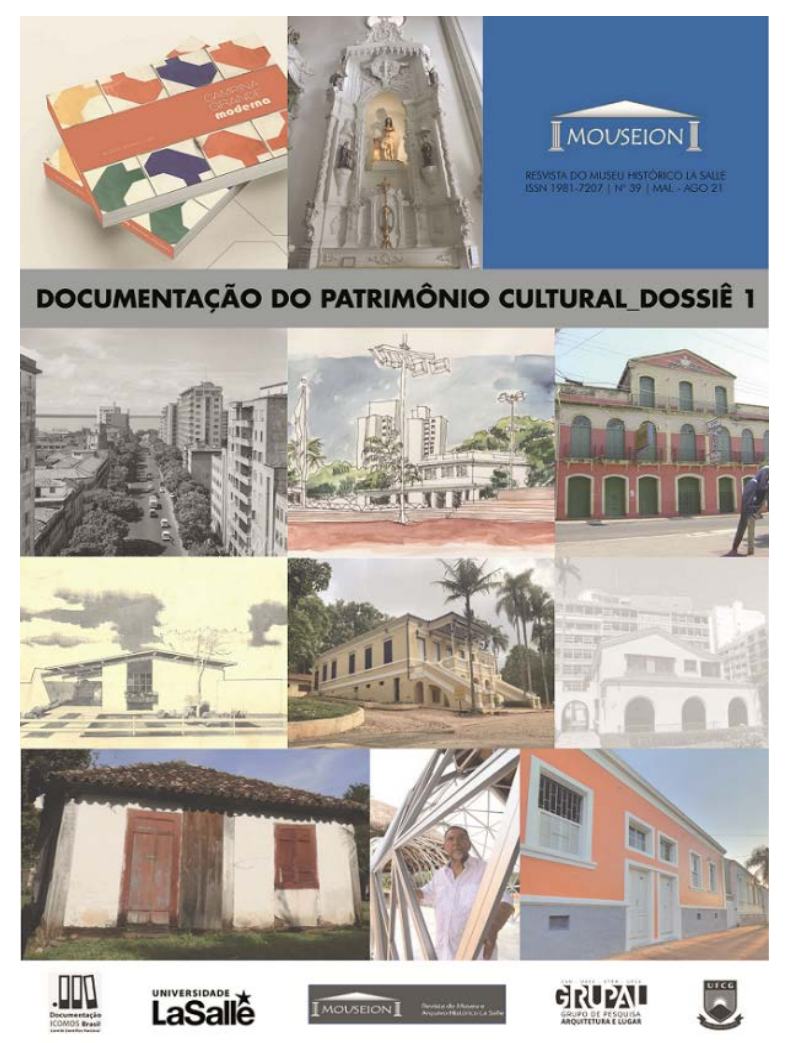

Figura 6 - Capa do primeiro dossiê na Revista Museion Fonte: https://revistas.unilasalle.edu.br/index.php/Mouseion/issue/view/347/showToc. Acesso em $11 / 10 / 2021$.

Mais uma vez a estratégia da aproximação do comitê com uma universidade sulista funcionou e conseguiu-se que um dos artigos tratasse da temática patrimonial 
da região sul. Contudo, as discussões patrimoniais desse dossiê se fizeram mais presentes na região nordeste e norte, com a presença de três artigos enfocando os acervos patrimoniais materiais e imateriais de cidades de Campina Grande/PB; Recife/ PE; Santarém /PA e Belém/ PA. O sudeste manteve sua média com dois artigos, tratando sobre o patrimônio barroco mineiro.

Nesse dossiê o tema voltado para a documentação da história da arquitetura foi o mais enfocado, com quatro artigos; juntamente com a da modernidade arquitetônica, presente com três artigos.

\section{Dossiê 6: Labor e Engenho/ Unicamp. São Paulo}

Uma das áreas de atuação da revista Labor e Engenho da UNICAMP/ Universidade Estadual de Campinas é o patrimônio ambiental e a paisagem cultural, e mais uma vez eu como coordenadora do IcomosDoc procurei a revista para realizar a parceria para a edição de mais um dossiê, que será divulgado não em um bloco, mas de forma contínua, pois a revista mudou recentemente sua forma de publicação.

Foram coletados doze artigos, tratando a maior parte do tema sobre o uso das ferramentas digitais relacionadas à salvaguarda patrimonial, demonstrando a força que possui a discussão no século XXI. As novas tecnologias como uso de VANT, laser escâner, reconstrução virtual através de programas gráficos, entre outros.

O tema da documentação da paisagem relacionada ao patrimônio e a construção da história da arquitetura brasileira através do resgate da documentação vieram logo em seguida, com dois artigos sobre cada tema. Dos artigos apresentados, três foram da região norte, especificamente de Belém; três da região nordeste, dois do centrooeste (de Brasília e Goiânia), três da região sudeste e apenas um da região sul, especificamente do estado do Rio Grande do Sul.

Dossiê 7: Revista Museion/ Uni La Salle. Rio Grande do Sul.

Com a finalidade de impulsionar mais a relação com o sul brasileiro, o lcomosDoc 
fechou mais uma parceria com a Revista Museion do Museu e Arquivo Histórico La Salle da cidade de Canoas no Rio Grande do Sul para um segundo dossiê, com onze artigos ( figura 7).
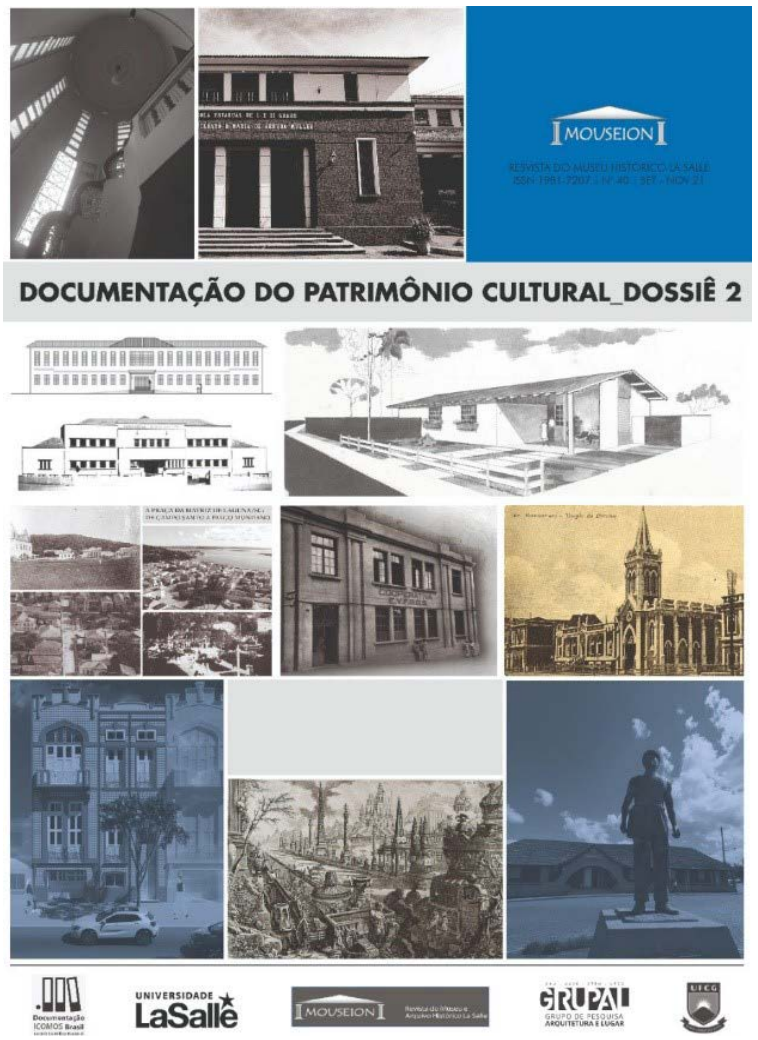

Figura 7 - Capa do segundo dossiê na Revista Museion Fonte: https://revistas.unilasalle.edu.br/index.php/Mouseion/index. Acesso em 11/10/2021

Seis artigos trataram sobre a documentação da arquitetura (história), três sobre paisagem e patrimônio, e outro sobre a teoria envolvendo a discussão documental.

A região nordeste participou com dois trabalhos sobre o patrimônio moderno presente em São Luís do Maranhão, e sobre o neogótico recifense. O sudeste representado por um trabalho voltado para o patrimônio de Jundiaí/SP; O sul esteve presente com um artigo sobre o Rio Grande do Sul, e um sobre a cidade de Laguna, em Santa Catarina, que por primeira vez, participou da publicação em dossiês.

O centro-oeste, foi mais uma vez representado por pesquisadores da UFG/ Universidade Federal de Goiás, que enviaram dois trabalhos referentes à cidade de Goiânia. Interessante foi um artigo tratando sobre o patrimônio arquitetônico de Cuiabá, 
que ainda é tão pouco discutido em nível nacional, sendo por isso, fundamental sua presença nesse trabalho de resgate em nível nacional da discussão patrimonial.

\section{Discussão}

A seguir, serão apresentados alguns resultados sobre a documentação do patrimônio cultural, observando-se a consolidação de uma rede nacional de pesquisa e o trabalho da elaboração de dossiês temáticos.

Analisando-se o gráfico da Figura 8, que apresenta o resultado dos artigos publicados nos dossiês por regiões brasileiras, o nordeste apareceu em primeiro lugar, com trinta e três publicações; em seguida, o sudeste com catorze artigos; a região norte e centro-oeste, em terceiro, com doze artigos; seguidos da região sul, com nove trabalhos.

\section{8}

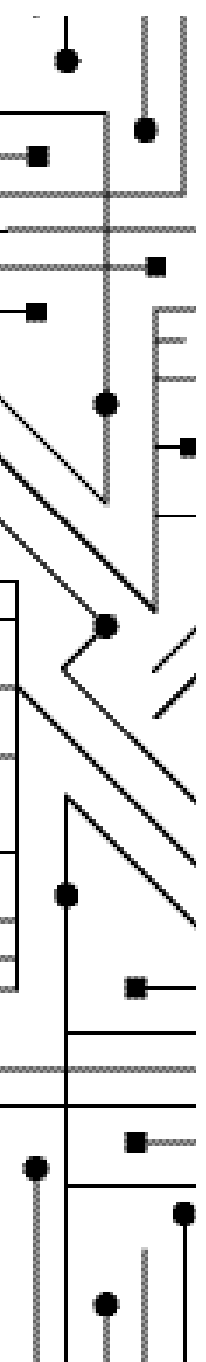

ARTIGOS PUBUCADOS NOS DOSSIÊS POR REGIÕES BRASILEIRAS E NO EXTERIOR

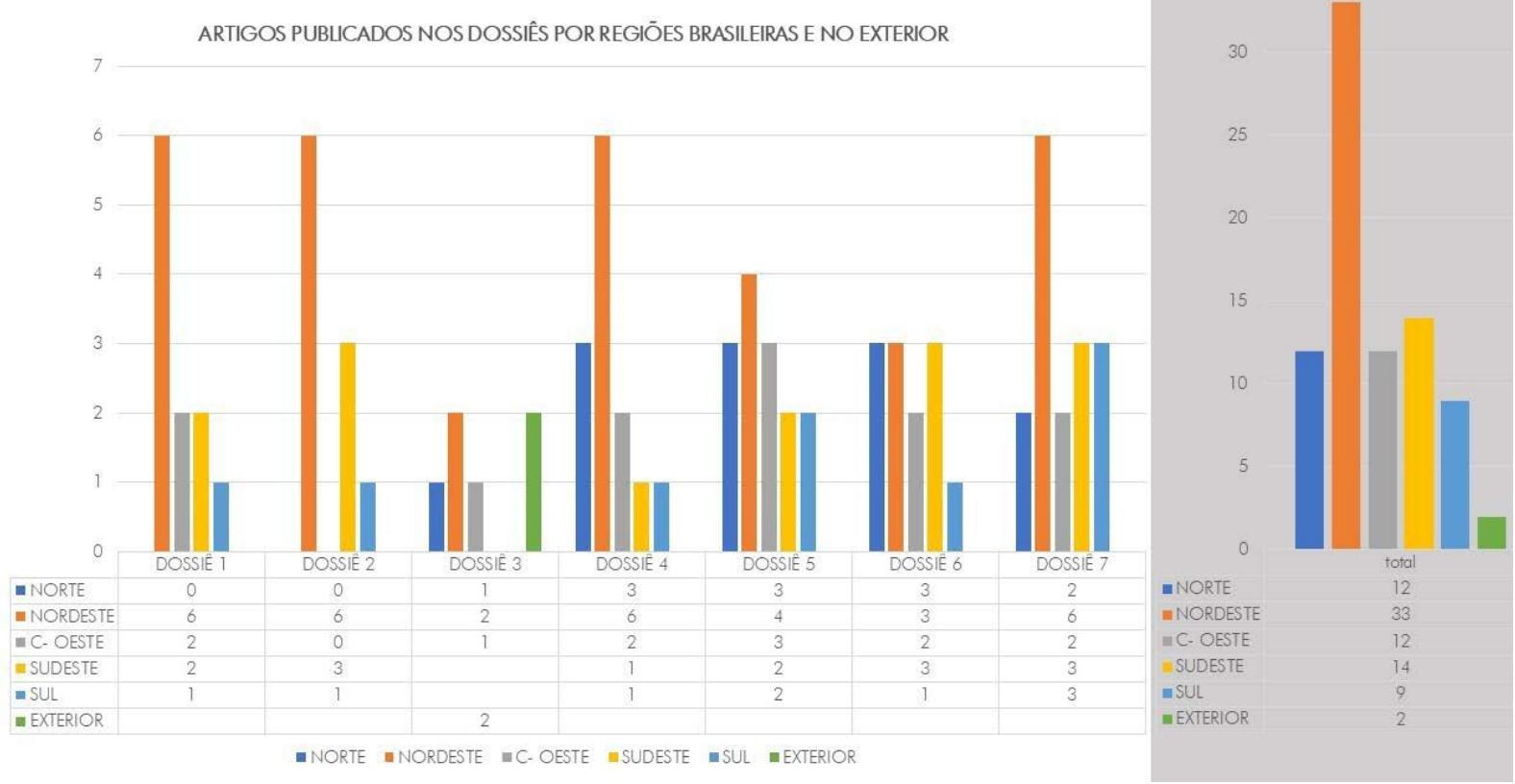

Figura 8 - Artigos publicados nos dossiês por regiões.

Fonte: Elaboração da autora.2021.

Conforme foi visto anteriormente, $35 \%$ dos membros do IcomosDoc atuam no nordeste, por isso, é justificável que a maior parte dos artigos tenha sido produzido 
sobre o cenário regional, o que foi muito bom, pois trouxe à tona, resultados importantes a respeito da preservação documental, e enfocando-se ali, principalmente, temas voltados à modernidade arquitetônica e à paisagem nordestina, dando "vez e voz" à região e sua cultura rica e diversa.

Observou-se ainda que a região norte possui um enfoque acadêmico que se consolida no cenário regional na UFPA/ Universidade Federal do Pará, através do pesquisas desenvolvidas no programa de pós-graduação em arquitetura e urbanismo, pois a maior parte dos trabalhos publicados da região foram oriundos do programa. Infelizmente, apesar das provocações em forma de convite para outros membros dos outros estados do norte participarem, apenas Roraima, participou, através da UFRR, que inclusive foi parceira em um dos dossiês, conforme foi visto anteriormente.

O centro-oeste vem despontando com a força da UFG/ Universidade Federal de Goiás, vinculado a pesquisadores do Programa de Pós-graduação Projeto e Cidade (PPGPC), demonstrando mais uma vez a importância da formação acadêmica em nível de pós-graduação para o desenvolvimento profissional e crítico do trabalho preservacionista.

Infelizmente, outros estados do centro-oeste e o distrito federal, não têm apresentado trabalhos nos dossiês. Sobre a causa da baixa participação da região sul, não se chegou ainda a uma justificativa, considerando-se que ali, existem bons cursos de graduação e programas de pós-graduação, que poderiam também estar envolvidos na rede nacional da pesquisa patrimonial.

Mas, e a região sudeste? Por que a sua fraca participação nas publicações, quando se sabe que ali existem tantas e boas universidades com cursos na área, e instituições preservacionistas? Seria, talvez porque eles se "autoalimentam" em seus próprios periódicos, e não estão dialogando com as demais regiões brasileiras? Seria uma reflexão a ser feita. Apenas, a UNICAMP vem demonstrando interesse na rede de pesquisa e no trabalho dos dossiês. 


\section{Conclusão}

Após a análise realizada observou-se que no total de setenta e três artigos publicados nos dossiês, os temas mais tratados foram aqueles referentes à documentação da modernidade, seguidos de artigos sobre a relação da paisagem com o patrimônio, e em terceiro lugar, aqueles voltados à historiografia arquitetônica em geral.

Despertou ainda a atenção, a boa quantidade de trabalhos tratando sobre o uso de ferramentas digitais, que obteve vários artigos sobre pesquisas desenvolvidas nas mais distintas regiões brasileiras, demonstrando a importância da tecnologia para a preservação patrimonial (figura 9).

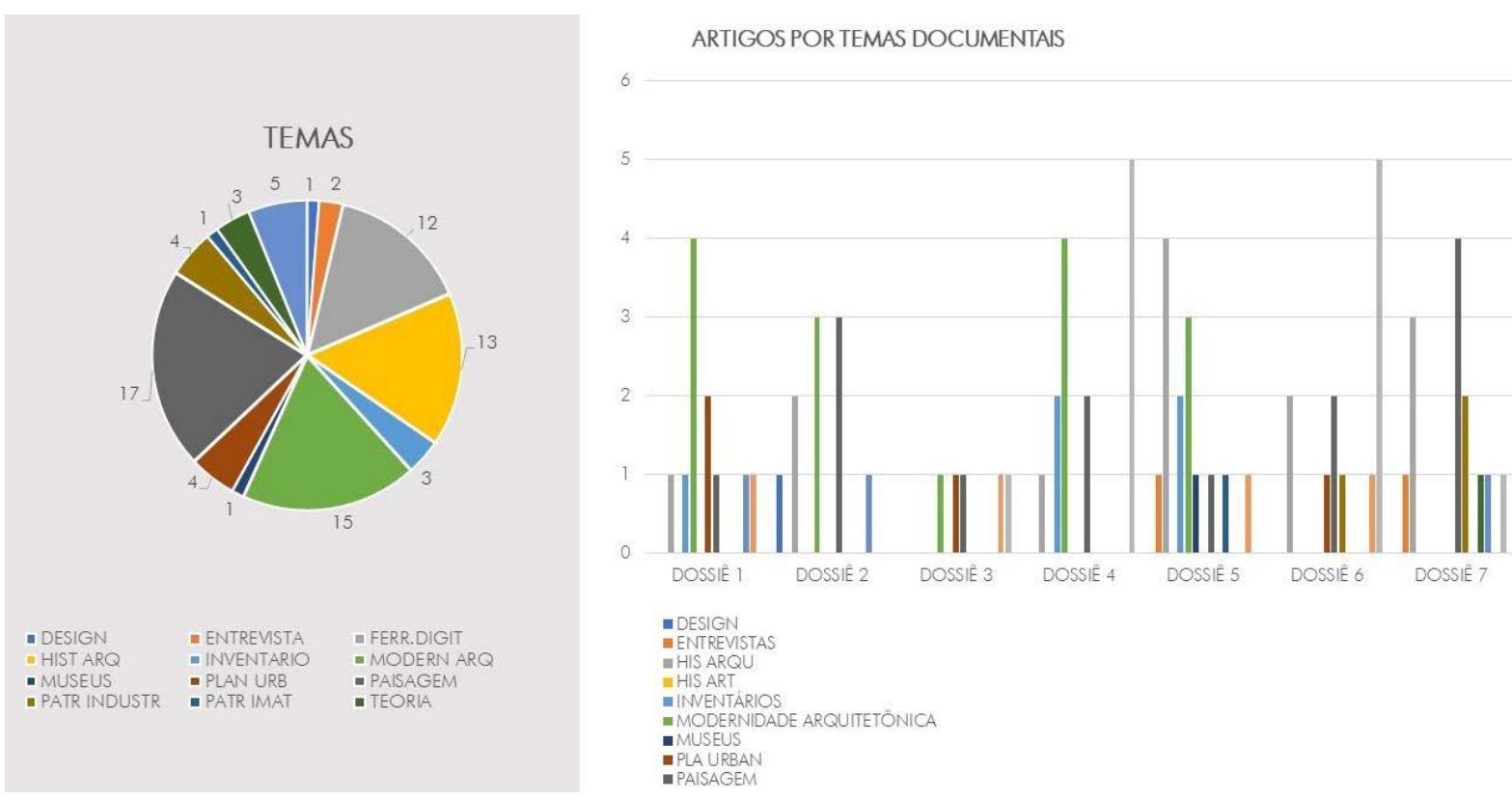

Figura 9 - Temas tratados nos dossiês por regiões. Fonte: Elaboração da autora.2021.

Esse artigo procurou de forma sucinta, expor especificamente uma ação realizada pelo IcomosDoc em prol da socialização das pesquisas na área realizadas por seus membros, mas, sabe-se que as omissões de participação de muitos estados não devem ser avaliadas como uma inexistência de reflexões ou ações.

Sem dúvida, a maior participação das temáticas sobre documentação da 
modernidade, e da paisagem, se devem ao maior empenho de alguns membros em se relacionar com colegas da rede e provocar a publicação dos artigos.

O trabalho em prol da valorização da documentação continua. Frisa-se que, no século $\mathrm{XXI}$, as políticas públicas brasileiras na área deveriam ser atualizadas, incentivando-se o uso de tecnologia da informação, ferramentas digitais, capacitação técnica, aparelhamento de arquivos públicos, no sentido de fomentar cada vez mais essa importante fase no processo de preservação patrimonial.

Infelizmente, o cenário brasileiro não é otimista, pois o patrimônio cultural não é uma prioridade na agenda pública. O abandono, o descaso, a falta de vontade política, e de incentivos vem apagando da memória a documentação patrimonial pelos riscos constantes que o acervo vem passando.

\section{Referências}

AFONSO, Alcilia e KALLAS, Luana (org). Dossiê de documentação. Revista Jatobá. Em rede: https://www.revistas.ufg.br/revjat/issue/view/2190. Acesso em 26/08/2021.

AFONSO, Alcilia (org). Dossiê de documentação: Arquitetura, Cidade e Documentação. Mnemosine Revista / Programa de Pós-Graduação em História. Centro de Humanidades. Universidade Federal de Campina Grande. V. 11 n.2 (2020). Campina Grande: CH/UFCG, 2020-Semestral. Em rede: http://www. mnemosinerevista.com/index.php/revista/issue/view/29/37. Acesso em 26/08/2021.

AFONSO, Alcilia (org). Documentação do patrimônio cultural_dossiê 1. Revista Museion. Em rede: https://revistas.unilasalle.edu.br/index.php/Mouseion/issue/ view/359. Acesso em 24/08/2021.

AFONSO, Alcilia (org). Documentação do patrimônio cultural_dossiê 2. Revista Museion. Em rede: https://revistas.unilasalle.edu.br/index.php/Mouseion/index. Acesso em 24/08/2021. 
AFONSO, Alcilia e COSTA, Graciete. (org). Edição Especial (2021): Dossiê Documentação do Patrimônio Cultural. Em rede: https://revista.ufrr.br/rct/issue/ view/318/showToc. Acesso em 20/08/2021.

AFONSO, Alcilia e ARGOLLO, André.(org). Dossiê Documentação do Patrimônio Cultural. Revista Labor \& Engenho. Em rede: https://periodicos.sbu.unicamp.br/ojs/ index.php/labore/article/view/8668057/27818. Acesso em 24/08/2021.

CIPA/ HERITAGE DOCUMENTATION. ICOMOS International Scientific Committee - ISPRS Permanent Committee (ISC) Statutes. Em rede: https://www. cipaheritagedocumentation.org/about/statutes/; Acesso em 3 de setembro de 2021.

CURY, Isabelle (org).Cartas Patrimoniais. $3^{a}$ Ed. Rio de Janeiro: IPHAN. 2000.

GIL, A. Métodos e técnicas de pesquisa social. 6. ed. São Paulo: Atlas, 2008.

ICOMOS. O cenário brasileiro e latino-americano da documentação do patrimônio: pesquisas, pesquisadores e instituições. (16/09/2020). Em rede: https://youtu.be/-peJKRE8v3k. Acesso em 26/08/2021.

ICOMOS. Tecnologias digitais para documentação: do vernáculo ao moderno. Webinar 2_(23 / 09 / 2020). Em rede: https://youtu.be/0aldi-042S0. Acesso em $26 / 08 / 2021$.

ICOMOS. A importância da documentação como forma de preservação do patrimônio cultural. Webinar 3_(dia 8/10/2020): Em rede: https://youtu.be/uaeyM_ tRvKM. Acesso em 26/08/2021.

ICOMOS. Os sketches no resgate e na valorização do patrimônio. Webinar 4 (dia 16/10/2020). Em rede: https://youtu.be/CjTJ0xlo0Rw. Acesso em 27/08/2021.

ICOMOS. A documentação para a compreensão da paisagem cultural. Webinar 5_(dia 30/10/2020). Em rede: https://youtu.be/x0RH_AYwC8k. Acesso em 25/08/2021. 
ICOMOS. Principios para la creación de archivos documentales de monumentos, conjuntos arquitectónicos y sitios históricos. 11a Asamblea General del ICOMOS. Sofía, Bulgaria. 1996. Acesso em 28/08/2021.

ICOMOS BRASIL. Missão e plano de ação do comitê científico nacional de documentação do Icomos Brasil, 2020. Em rede: https://www.icomos.org.br/ documentacao. Acesso em 25/08/2021.

\section{NOTAS}

Artigo publicado originalmente no 7o. Seminário iberoamericano arquitetura e documentação. 6 out 2021. Eixo temático 3 -Arquitetura e documentação: a pesquisa na área da história da Arquitetura e do Urbanism e depois, ampliado, revisado e atualizado para esse artigo.

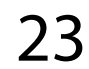

\section{$\downarrow \mid$ Publisher}

Universidade Federal de Goiás. Faculdade/Instituto/Escola. Programa de Pós-graduação Projeto e Cidade. Publicação no Portal de Periódicos UFG. As ideias expressadas neste artigo são de responsabilidade de seus autores, não representando, necessariamente, a opinião dos editores ou da universidade.

RECEBIDO EM: 01/11/2021

APROVADO EM: 24/12/2021

PUBLICADO EM: 30/12/2021 